\title{
Existing Situation of on Street Parking and Impacts on Effective Carriageway Width and V/C Ratio: A Case Study of Rajshahi City Corporation Area
}

\author{
Aftabun Nahar", Rupesh Chakma, Nayem Uddin, Anutosh Das \\ Department of Urban and Regional Planning, Rajshahi University of Engineering and Technology, Rajshahi, Bangladesh \\ Email address: \\ himu2010.13@gmail.com (A. Nahar) \\ ${ }^{*}$ Corresponding author
}

\section{To cite this article:}

Aftabun Nahar, Rupesh Chakma, Nayem Uddin, Anutosh Das. Existing Situation of on Street Parking and Impacts on Effective Carriageway Width and V/C Ratio: A Case Study of Rajshahi City Corporation Area. International Journal of Science, Technology and Society. Vol. 6, No. 2, 2018, pp. 33-42. doi: 10.11648/j.ijsts.20180602.12

Received: August 12, 2017; Accepted: September 29, 2017; Published: May 25, 2018

\begin{abstract}
Rajshahi is an important and divisional city of Bangladesh. Rajshahi city has well organized internal communication as well as connection to other parts of the country. But, the growth of slow moving vehicles such as easy bike and auto rickshaws in Rajshahi has created many problems. One of the worst issues is, being parked these vehicles at the major intersection points. It is becoming a crucial issue in managing the transportation system since it affects the overall accessibility of a city. On street parking is now creating severe transportation problems in major roads of Rajshahi city. Moreover, on street parking is one of the main reasons of road congestion in Rajshahi city. This paper aims to explicate the parking scenario of the major intersection of Rajshahi city of slow moving vehicle traffic through analyzing the parking location, modal share of parking and parking supply analysis such as accumulation rate, volume, load, duration, occupancy, turn over etc. Required data has been collected from four major intersections named as Talaimari, Laxmipur, Monichottor and Railgate in Rajshahi city corporation area from 8.30AM to $12.00 \mathrm{AM}$ by using parking space inventory method and parking usage survey by petrol. Traffic volume count survey is also conducted to know the effects on $\mathrm{V} / \mathrm{C}$ ratio with and without parking. The study found that the Monichottor intersection has the worst condition, even the level of service of the road is fallen because of the illegal on street parking. It also provides the comparisons between designated parking bay and non-designated place of parking. This study can help to explore the possibilities of moderating the present parking problems of Rajshahi. As the traffic on the existing road system increases, congestion becomes serious problems. Thus there could be medium and long term solution measures.
\end{abstract}

Keywords: Rajshahi, Slow Moving Vehicle Traffic, On Street Parking Scenario, Major Intersections, V/C Ratio, Effective Carriageway Width

\section{Introduction}

Rajshahi is an important and the busiest city in Bangladesh because of its educational, commercial, trade, administrative activities. It is called educational city of the country. Activities of the city are growing up day by day as a result traffic congestion also increases due to the increasing number of slow moving vehicle. Before 2008, rickshaw was the major transport vehicle in Rajshahi City Corporation area for travelling short distance [1]. But now battery run auto rickshaw has become popular for easy travelling and cheap cost than other locally available transport modes. Auto rickshaw reduces the unemployment rate about $2 \%$ in Bangladesh [2]. It also provides reasonable safety and comfort to the users during travel. There are nearly than 15,000 battery operated easy bike, 7000 auto - rickshaws in Rajshahi Metropolitan area. According to the RAJSHAHI CITY CORPORATION sources, there are more than 10,000 easy bikes and 5000 auto rickshaws moving in the city area and the Rajshahi City Corporation officials claimed that they 
have license to 10,000 easy bikes and 4000 auto rickshaws [3]. The present condition of parking have worsened because of the numbers of auto rickshaws have recklessly increased. This study try to show the existing on street parking status of Rajshahi City Corporation area. Parking space inventory and parking usage survey method by petrol are conducted to know the actual scenario. This study also shows the impacts of on street parking on effective carriageway width and $\mathrm{V} / \mathrm{C}$ ratio. Traffic volume count survey is conducted for calculating volume of intersections. The previous researches are concerned only parking accumulation at major spots rather than the other parking supply analysis. The four intersections are (Talaimari, Laxmipur, Monichottor and Railgate) chosen for this study due to being focal point of Rajshahi. It is easy to make a comparative analysis of designated and non-designated parking among them and to evaluate the parking condition of Rajshahi. This report focuses on accommodating future city growth and parking in a sustainable and fiscally responsible manner. It will be helpful for transport planner to design an efficient parking environment in Rajshahi and will give a scope for further research.

\section{Methodology}

The principal objective of this study is to show the existing situation of on street parking and effects on $\mathrm{V} / \mathrm{C}$ ratio as stated in introduction. For notifying the actual scenario, three types of survey methods are conducted. The present study includes four major intersections of Rajshahi. For this study, literatures are reviewed for two times. First one is for choosing the topic and to know about parking statistics and second one is for choosing survey methods. The study takes overview some reports to analyze the objectives. These help to understand how can get the result. It also provides working procedure. The first step is to collect data on the amount, type and location of space actually or potentially available for parking in an area by parking space inventory method and parking usage survey by patrol. The purpose of parking usage survey is to obtain data on the extent of usage of parking spaces [4]. These information can help to guide decisions making and to ensure that parking is provided and priced at rates that meet the needs of commuters, visitors, businesses, and residents, while also advancing the City's broader goals of economic development and sustainability [5].

After selecting survey method, the working day is selected to collect the data. In Rajshahi city the weekend day does not vary highly from the working day on transportation sector. The data is collected from four selected intersection. Parking usage survey by patrol had been conducted on the following day which included counting parked vehicles at 30 minutes intervals through a period of 3.5 hours.

The level of service is defined in order to Transportation Research Board circular 212 planning method [6] stated at table 1 .
Table 1. Level of Service Defined by V/C Ratio.

\begin{tabular}{ll}
\hline V/C ratio & Level of Service \\
\hline$<0.6$ & $\mathrm{~A}$ \\
$0.60-0.69$ & $\mathrm{~B}$ \\
$0.70-0.79$ & $\mathrm{C}$ \\
$0.80-0.89$ & $\mathrm{D}$ \\
$0.90-0.99$ & $\mathrm{E}$ \\
$0.99-1.00$ & $\mathrm{~F}$ \\
\hline
\end{tabular}

Source: TRB circular 212 planning method

For calculating V/C ratio, the design Capacity is measured by this following formula

$$
\text { Design capacity }=(\text { Effective width } / 12) * 1400
$$

All collected data are inputted and finally by using Microsoft Excel software, major findings are found.

\section{Literature Review}

Parking denotes the basic requirement in a transportation system. But more often its impact on the efficiency of traffic movement evades our contemplation. This is because our perception of transportation is limited with the notion of movement whereas parking involves the condition when the vehicles are stationary. It is becoming a crucial issue in managing the transportation system since it affects the overall accessibility of a city [7].

This becomes more critical in transportation management scenario like that prevailing in Rajshahi city where most people prefers to use easy bike and auto rickshaws in the busy commercial centers and intersections. A study conducted by Tanzim and Miah [8] revealed that the highest parking accumulation rate at Railgate parking spot and the lowest is at Vodra parking spot and emphasized that as the traffic on the existing road system increases, congestion becomes serious problems. And they suggest that there could be medium and long term solution measures. Thus the viability of the major intersections depends on the availability of convenient parking facilities adjacent to or easily accessible to desired destinations, especially off-street parking facilities.

An another study [9] revealed that the average duration of parking in New Market area is around 45 minutes and a considerable portion of cars occupy the parking area up to 3 to 5 hours which lessens parking turnover. This study mainly explicate the parking scenario of New Market, which is a very popular shopping center of this city through analyzing the parking and demand supply and try to explore the possibilities of moderating the present parking problems of this market. Parking space inventory and parking usage survey by patrol methods have conducted on two separate working days each covering five hour periods. Based on the findings of the study, some policies are suggested to prevail the adverse condition.

As pointed out by Banu and Rahman [10] that $60 \%$ of the organizations do not have adequate parking facility as specified in Bangladesh National Building Code. Parking 
supply is not enough for fulfill the demand. As a result, improper management, operation and maintenance are also in some cases. Due to the lack of proper parking facilities and strict regulations, on street parking has become a very common phenomenon in Dhaka city which decreases the roadway capacity and creates severe problems like congestion, delay, accident potentiality and some other relevant problems. This study revealed that $50-65 \%$ reduction in roadway capacity due to on street parking is found on the roads of Shapla Square, Motijheel. The percentage of reduction is $52 \%$ in case of Mirpur Road in front of New Market. 43\% reduction in operating speed is found due to on street parking on Mirpur Road.

\section{Data Analysis and Result}

As it is stated into Methodology, three survey methods are used in this study for fulfilling the objectives. The objectives of the study is to find out the existing situation and to determine the effects on $\mathrm{V} / \mathrm{C}$ ratio of with and without on street parking. Four intersections are analyzed differently and different results are found.

\subsection{Talaimari Intersection}

Talaimari is an intersection of Dhaka-Rajshahi highway. It is a non-signalized and three legs intersection. The location of parking is on the road and beside the road at the south side of the intersection shown in figure 1. Parking on road is totally illegal parking. Though there is place for parking beside the road, drivers park the vehicles on the road for more passenger. There are three types of mode of parked vehicles such as easy bike (55\%), auto rickshaw (26\%) and bicycle $(19 \%)$. Bicycles are parked only beside the road which is separated from the main road. Bicycle holders are mainly workers or day labor.

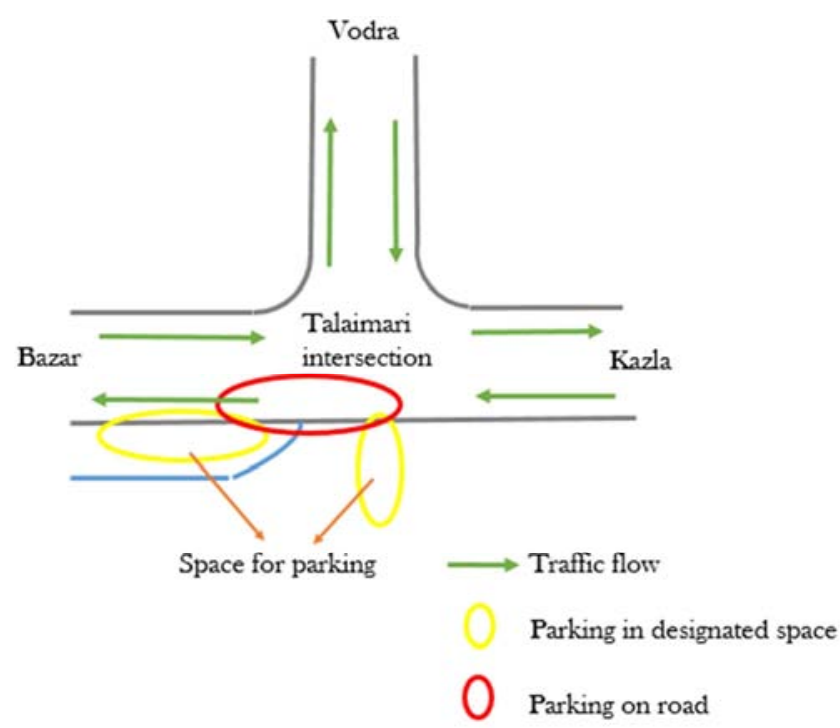

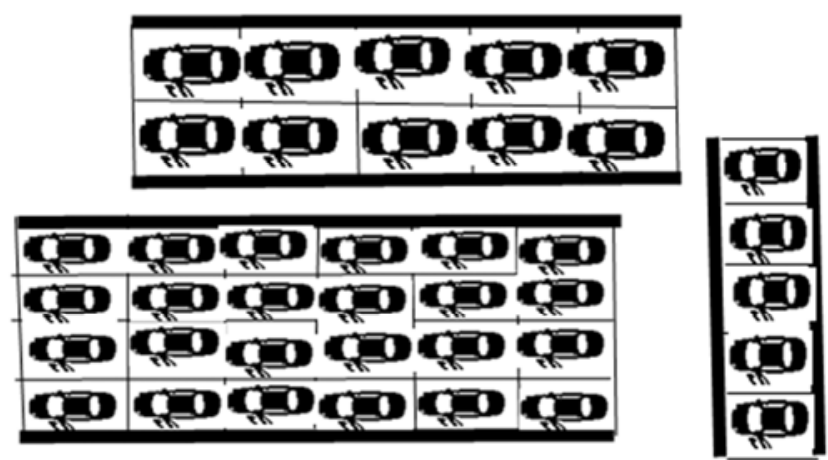

Source: Field survey, 2017.

Figure 1. Location of Parking in Talaimari.

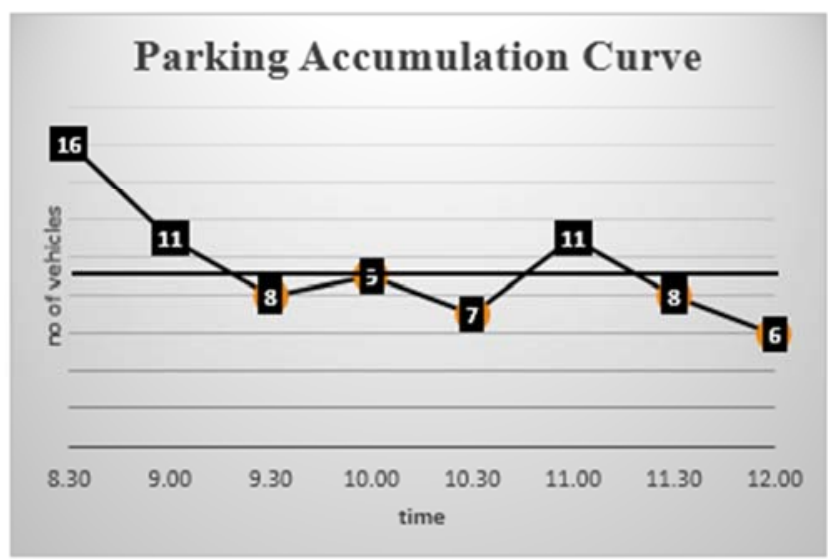

Parking Accumulation Curve

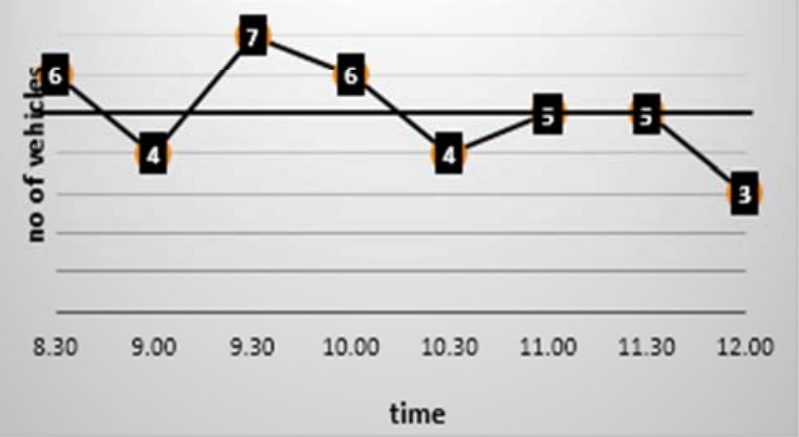

Source: Field survey, 2017.

Figure 2. Accumulation curve of Parking in Designated Space and Parking on Road (from up to down) in Talaimari.

\subsubsection{Parking in Designated Space}

Total parking volume over a period of 3.5 hours is 76 vehicles (figure 2). So, the average volume is 21.71 vehicles/hour. That means on an average in every hour 21.71 new vehicles come into this parking bays. There exist 29 available parking space in this intersection for 76 vehicles. So, Parking turnover is $2.62(76 / 29)$ vehicles per space over a time period of 3.5 hours. It indicates that every space is used by 2.62 vehicles over the time period. The parking alignment technique is mix (90 degree and parallel). And average parking duration is 35 minutes. 


\subsubsection{Parking on Road}

Total parking volume over a period of 3.5 hours is 41 vehicles (figure 2). So, the average volume is 11.71 vehicles/hour. That means on an average in every hour 11.71 new vehicles come into this intersection. There exist 10 available parking space in this intersection for 41 vehicles. So, Parking turnover is $4.1(41 / 10)$ vehicles per space over a time period of 3.5 hours. This turnover figure represents that available parking spaces are not used efficiently. The parking alignment technique is parallel. And average parking duration is 10.5 minutes.

\subsubsection{Impact on V/C Ratio}

The formula of calculating design capacity and the Level of Service defining method are stated in methodology. In case of Talaimari intersection, the total carriageway width of road is 40 feet. Usually easy bike and auto rickshaw have been parked in two extra rows which require a total road width of 32 feet. Road width used by normal traffic flow has thus been reduced to a mere 8 feet shown in table 2 .

Table 2. V/C ratio of road with and without on-street parking in Talaimari.

\begin{tabular}{llllll}
\hline On Street Parking & Effective Carriageway width (ft) & Capacity (PCU/hr) & Service volume (PCU/hr) & V/C ratio & Level of Services \\
\hline With parking & 32 & 3733 & 1320.6 & 0.35 & $\mathrm{~A}$ \\
Without parking & 40 & 4667 & 1320.6 & 0.28 & $\mathrm{~A}$ \\
\hline
\end{tabular}

Source: Field survey, 2017.

Obviously there have been impacts on carriageway width and $\mathrm{V} / \mathrm{C}$ ratio, but no significant change in level of service.

\subsection{Laxmipur Intersection}

Laxmipur is a signalized intersection, but signal does not work. It is a four legs intersection. In location A (East side of intersection), parking of slow moving vehicles are on the road and beside the road. And in location B (North side of intersection), parking of slow moving vehicles are only on the road (figure 3 ). Parking on road is totally illegal parking. Though there is place for parking beside the road, drivers intentionally park the vehicles on the road for more passenger (location A). But in location $\mathrm{B}$, there is no additional place for parking. That's why, drivers park the vehicles on road. In Laxmipur intersection there are four types of parked vehicles such as bicycle, easy bike, auto rickshaw and van. The number of bicycles is more, because day labours are coming from nearest district for searching work. They use bicycle as a mode of transport.

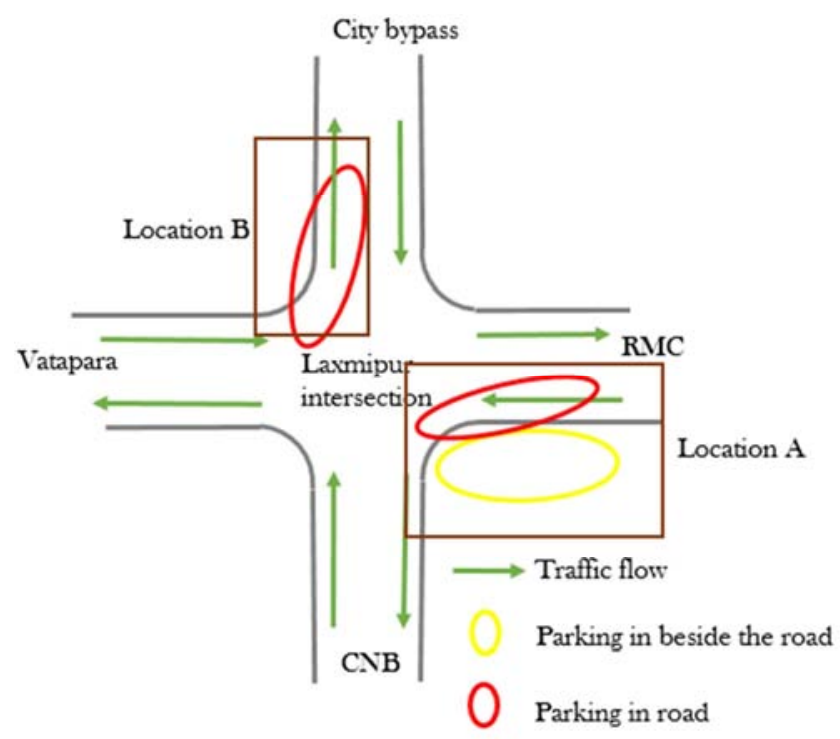

Location B

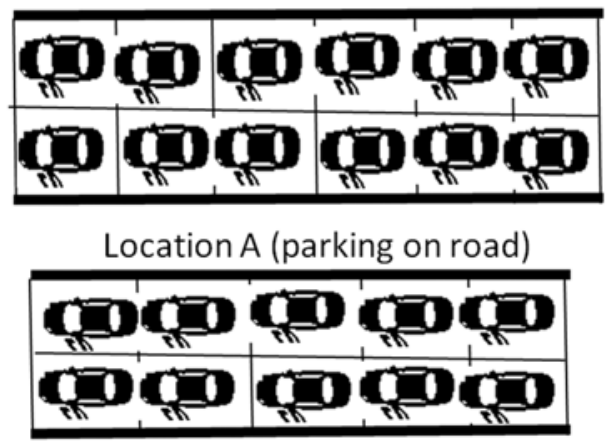

Source: Field survey, 2017.

Figure 3. Location of Parking in Laxmipur

\subsubsection{Parking at Location $A$}

Total parking volume over a period of 3.5 hours is 134 vehicles (figure 4). So, the average volume is 38.28 vehicles/hour. That means on an average in every hour 38.28 new vehicles come into this parking bays. The parking alignment technique is mix (90 degree and parallel). And average duration of parking is 55 minutes. The parking accumulation curve is falling significantly, because, day labors park their bicycle in beside the road as stated location of parking. And they are waiting until get any work. Within 10.00 AM they get their job and after that there is no bicycle.

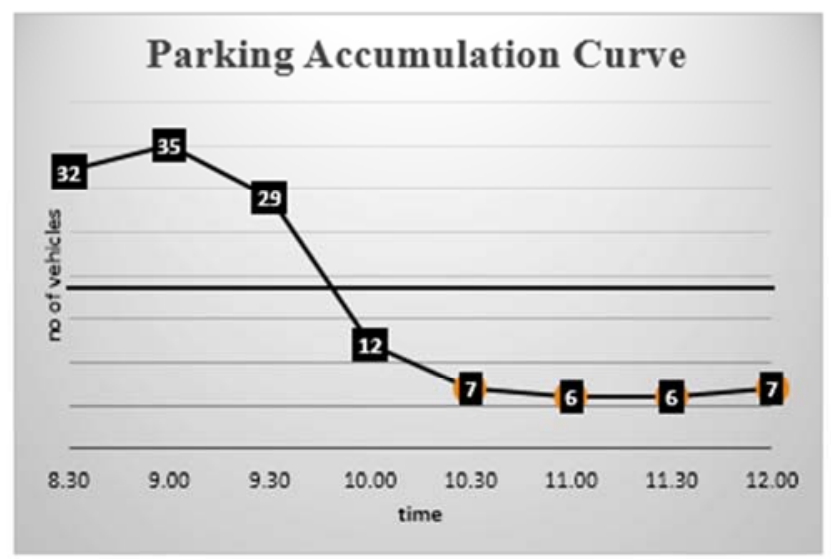




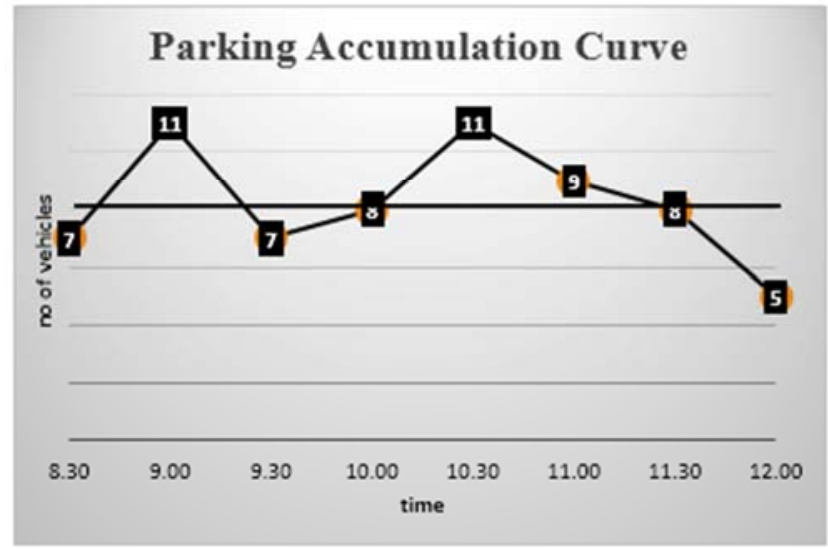

Source: Field survey, 2017.

Figure 4. Accumulation curve of Parking at Location A and Location B in Laxmipur.

\subsubsection{Parking at Location $B$}

Total parking volume over a period of 3.5 hours is 66 vehicles (figure 4). So, the average volume is 17.14 vehicles/hour. That means on an average in every hour 17.14 new vehicles come into this parking bays. There exist 12 available parking space in this intersection for 66 vehicles. So, the parking turnover is $5.5(66 / 12)$ vehicles per space over a time period of 3.5 hours. This turnover figure represents that available parking spaces are not used efficiently. The parking alignment technique is parallel. And average parking duration is 14.5 minutes.

\subsubsection{Impact on $V / C$ Ratio}

There is a little bit difference between location A and B. On street parking covers approximately $48 \%$ portion of road width at location A and $20 \%$ at location B. More changes in $\mathrm{V} / \mathrm{C}$ ratio is occurred at location a shown in table 3.

Table 3. V/C ratio of road with and without on street parking in Laxmipur.

\begin{tabular}{lllll}
\hline On street parking & $\begin{array}{l}\text { Effective carriageway } \\
\text { width (ft) }\end{array}$ & $\begin{array}{l}\text { Capacity } \\
\text { (PCU/hr) }\end{array}$ & $\begin{array}{l}\text { Service volume } \\
\text { (PCU/hr) }\end{array}$ & V/C ratio \\
\hline With parking (Location A) & 14 & 1633.33 & 799.4 & 0.48 \\
Without parking (Location A) & 26.5 & 3091.66 & 799.4 & 0.26 \\
With parking (Location B) & 26 & 3033.33 & 705.4 & 0.23 \\
Without parking (Location B) & 32 & 3733.33 & 705.4 & A \\
\hline
\end{tabular}

Source: Field survey, 2017

Though there has a significant difference in $\mathrm{V} / \mathrm{C}$ ratio, there will not any change in Level of Service.

\subsection{Monichottor Intersection}

Monichottor is a non-signalized and three legs intersection. In location A (East side of intersection), parking of slow moving vehicles are on the road. And in case of location B (North side of intersection), parking of slow moving vehicles are also on the road shown in figure 5. Because there are no space for parking

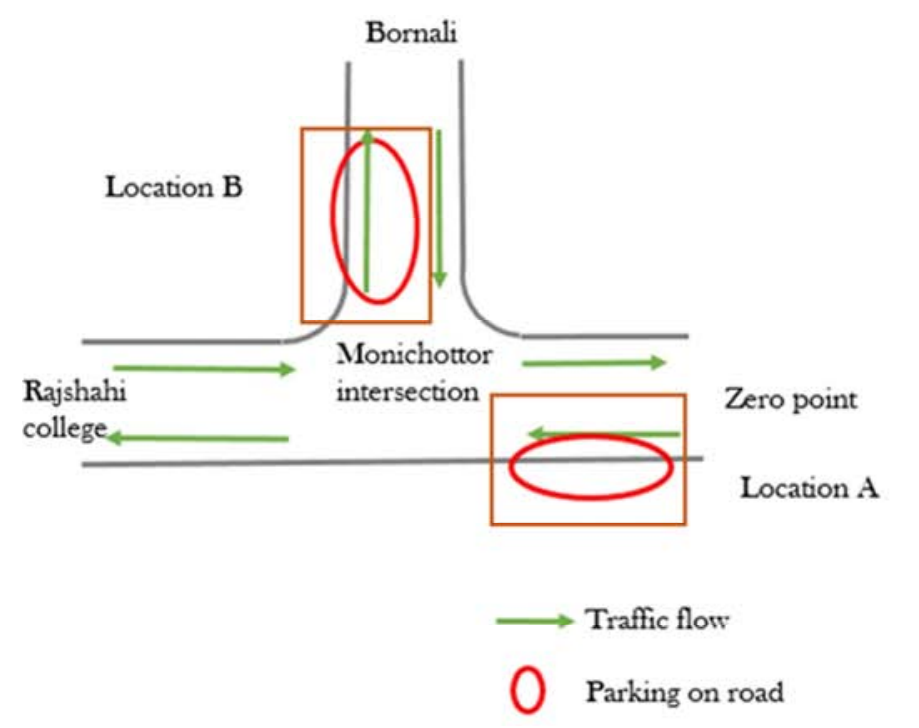

beside the road. Parking on road is totally illegal parking. For location A, there are four types of parked vehicles. Auto rickshaw occupies more space, then easy bike, van and bicycle. The number of auto rickshaws is more, because peoples are coming for shopping in katcha bazar. They use mainly auto rickshaws as a mode of transport rather than easy bike. Vans are coming for collecting vegetables. In location $\mathrm{B}$, there are also four types of parked vehicles. Easy bikes occupy major portion of parked space rather than auto rickshaws.

Source: Field survey, 2017

Figure 5. Location of Parking in Monichottor. 


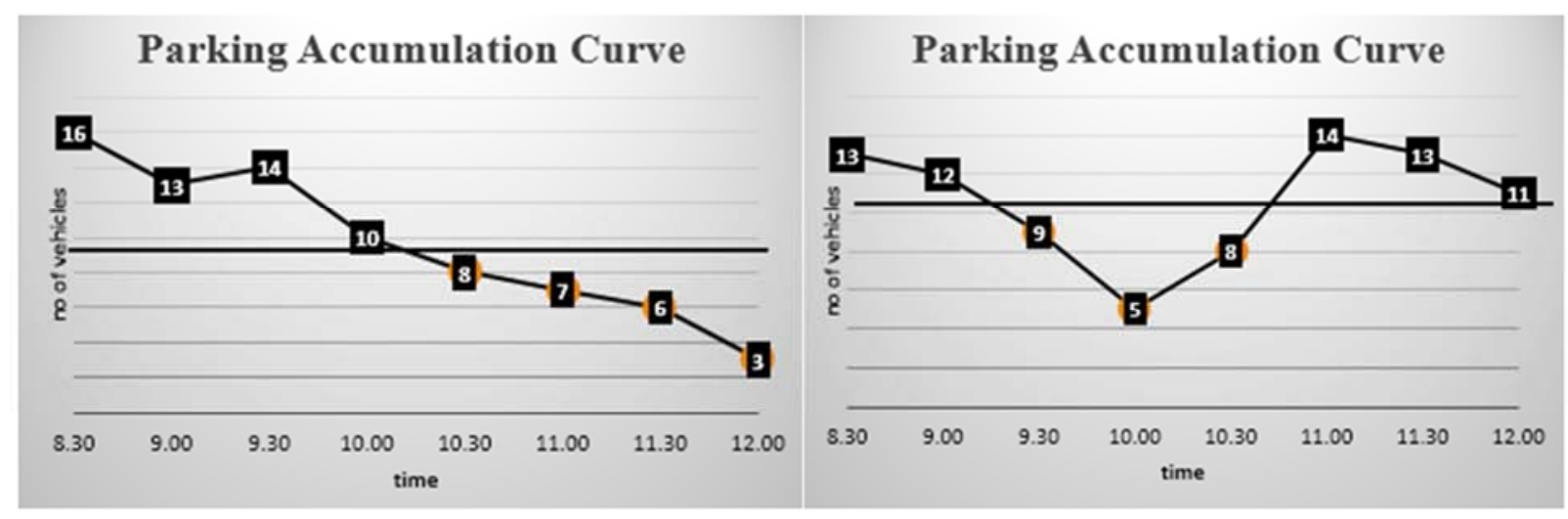

Source: Field survey, 2017

Figure 6. Accumulation curve of Parking at Location A and Location B (from left to right) in Monichottor.

\subsubsection{Parking at Location $A$}

Total parking volume over a period of 3.5 hours is 77 vehicles (figure 6). So, the average volume is 22 vehicles/hour. That means on an average in every hour 22 new vehicles come into this parking bays. There exist 12 available parking space in this intersection for 77 vehicles. So, the parking turnover is $6.41(77 / 12)$ vehicles per space over a time period of 3.5 hours. It indicates that every space is used by 6.41 vehicles over the time period. This turnover figure represents that available parking spaces are not used efficiently. The parking alignment technique is parallel. And average parking duration is 8 minutes

\subsubsection{Parking at Location B}

Total parking volume over a period of 3.5 hours is 85 vehicles (figure 6). So, the average volume is 24.28 vehicles/hour. That means on an average in every hour 24.28 new vehicles come into this intersection. There exist 16 available parking space in this intersection for 85 vehicles. So, parking turnover is $5.31(85 / 16$, stated at study area profile) vehicles per space over a time period of 3.5 hours. This turnover figure represents that available parking spaces are not used efficiently. The parking alignment technique is parallel. And average parking duration is 13.5 minutes.

\subsubsection{Impact on V/C Ratio}

There have not enough space for on street parking. In case of location A, effective carriageway width is $8 \mathrm{ft}$. and $22 \mathrm{ft}$. and for location B the width is $9.5 \mathrm{ft}$. and $26.5 \mathrm{ft}$ with and without parking respectively. In the table 4 all the information has given. However Capacity is too poor and $\mathrm{V} / \mathrm{C}$ ratio is larger. Here it has found a huge number of variation in level of service like from level of service B to level of service $F$ (Table 4).

Table 4. V/C ratio of road with and without on street parking in Monichottor.

\begin{tabular}{llllll}
\hline On street parking & $\begin{array}{l}\text { Effective carriageway } \\
\text { width }(\mathbf{f t})\end{array}$ & $\begin{array}{l}\text { Capacity } \\
\text { (PCU/hr) }\end{array}$ & $\begin{array}{l}\text { Service volume } \\
\text { (PCU/hr) }\end{array}$ & V/C ratio & Level of service \\
\hline With parking (Location A) & 8 & 933.33 & 2310.1 & 2.47 & $\mathrm{~F}$ \\
Without parking (Location A) & 22 & 2566.66 & 2310.1 & 0.90 & $\mathrm{D}$ \\
With parking (Location B) & 9.2 & 1091.66 & 1715.8 & 1.59 & $\mathrm{~F}$ \\
Without parking (Location B) & 26.5 & 3091.66 & 1715.8 & 0.55 & $\mathrm{~B}$ \\
\hline
\end{tabular}

Source: Field survey, 2017.

In addition the condition with parking both location $\mathrm{A}$ and $\mathrm{B}$ is too congested. For location A and B the level of service is $\mathrm{D}$ and $\mathrm{B}$ (without parking) and $\mathrm{F}$ and $\mathrm{F}$ for with parking. It will affect the overall connectivity of Rajshahi city in future.

\subsection{Railgate Intersection}

Railgate is the busiest intersection among these four intersection. It is a four legs intersection. In location A (East side of intersection), parking of slow moving vehicles are on the road and beside the road. And in location B (West side of intersection), parking of slow moving vehicles are only on the road shown in figure 7. Parking on road is totally illegal parking. Though there is place for parking beside the road, drivers intentionally park the vehicles on the road for more passenger (location A). There are four types of parked vehicles in location A such as bicycle, easy bike, auto rickshaw and van. Easy bikes and auto rickshaws are parked on the road and beside the road both, but bicycles and vans are parked only beside the road. In location B, there are two types of parked vehicles. Easy bikes occupy major portion of parked space. 
Table 5. V/C ratio of road with and without on street parking in Railgate.

\begin{tabular}{|c|c|c|c|c|c|}
\hline On street parking & $\begin{array}{l}\text { Effective carriageway } \\
\text { width (ft) }\end{array}$ & $\begin{array}{l}\text { Capacity } \\
(\mathrm{PCU} / \mathrm{hr})\end{array}$ & $\begin{array}{l}\text { Service volume } \\
\text { (PCU/hr) }\end{array}$ & $\mathrm{V} / \mathrm{C}$ ratio & Level of service \\
\hline With parking (Location A) & 38.5 & 4491.66 & 766.2 & 0.17 & A \\
\hline Without parking (Location A) & 46.7 & 5448.33 & 766.2 & 0.14 & A \\
\hline With parking (Location B) & 36.2 & 4223.33 & 1346.6 & 0.32 & A \\
\hline Without parking (Location B) & 52 & 6066.66 & 1346.6 & 0.22 & A \\
\hline
\end{tabular}

Source: Field survey, 2017.

It has enough capacity with respect to volume of traffic condition. The overall condition in Railgate intersection is likely good in compare with level of service and $\mathrm{V} / \mathrm{C}$ ratio.

\subsection{Comparative Analysis}

Comparative analysis is very important to show the actual differences. In this study, comparative study indicates the practical differences that will be helpful for providing parking facility according to the need. Generally, the need of parking is high in non-designated spaces rather than designated space. For comparative analysis, Talaimari (parking on designated space) and Railgate (parking on designated space, location A) and Laxmipur (parking on road, location A) and Monichottor (location A) are selected as designated and non-designated space respectively.

There has a significant differences between parking on road and parking in beside the road or designated spaces. Basically, differences are found in parking techniques, parked vehicles, average duration and turn over. The differences are shown in table 6 .

Table 6. Comparison between designated and non-designated parking.

\begin{tabular}{lllll}
\hline \multirow{2}{*}{ Variables } & Designated parking space & Non designated parking & Monichottor \\
\cline { 2 - 5 } & Talaimari & Railgate & Laxmipur & Parallel \\
\hline Parking techniques & Mix $(90$ and parallel) & Mix $(90$ and parallel) & Parallel & Easy bike, auto rickshaw \\
Parked vehicles & Bicycle, easy bike, auto & Bicycle, easy bike, auto & Easy bike, auto rickshaw & and van \\
Average duration (minute) & rickshaw and van & rickshaw and van & and van & 8 minutes \\
Turn over & 25 minutes & 42 minutes & 9 minutes & 6.41 \\
\hline
\end{tabular}

Source: Field survey, 2017.

$\mathrm{V} / \mathrm{C}$ ratio is the another factor which has a different characteristic in designated and non-designated places of parking. Table 5 shows the real scenario of this matter. In designated spaces, the change of $\mathrm{V} / \mathrm{C}$ ratio is low compared to the parking on road according to with and without parking such as in Talaimari intersection the change is from 0.28 to 0.35 (shown in figure 9). The difference is only 0.7

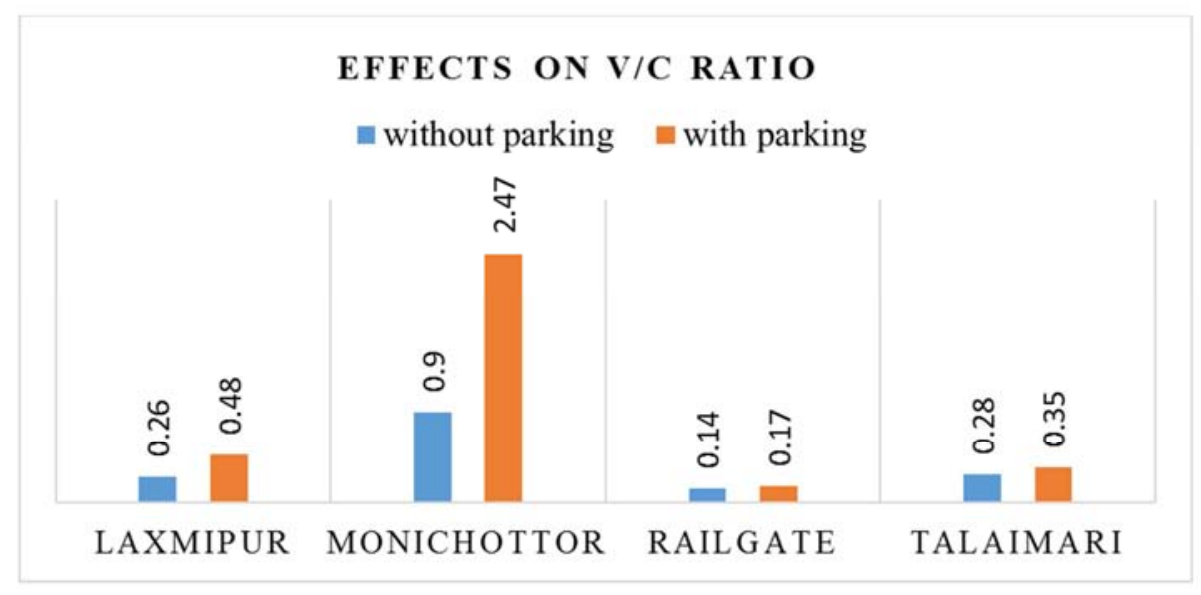

Source: Field survey, 2017.

Figure 9. Changes in V/C ratio with and without parking.

In case of non-designated place, the change of $\mathrm{V} / \mathrm{C}$ ratio is more compared to the designated parking such as in Monichottor intersection the change is from 0.9 to 2.47 (shown in figure 9). The difference is only 1.57. It indicates that parking on road has a great impact on $\mathrm{V} / \mathrm{C}$ ratio and effective carriageway width. And it will become a threat for efficient transportation system.

\section{Conclusion}

Rajshahi is one of the most important divisional district in Bangladesh. In modern time day by day parking has become 
a greatest important issue. According to the analysis purpose four major intersection has chosen like Talaimari, Monichottor, Railgate and Laxmipur. In this case study the main objectives are to find out the existing situation of on street parking of Slow Moving Vehicle at major intersections of Rajshahi City Corporation area and to determine the impacts of on street parking on effective carriageway width and $\mathrm{V} / \mathrm{C}$ ratio of selected roads with and without on street parking. For the first objective perspective existing situation of parking has shown as location of parking, modal share of parked vehicles and parking supply analysis studied in details. Then it also covers the $2^{\text {nd }}$ objective impact of on street parking on effective carriageway width and $\mathrm{V} / \mathrm{C}$ ratio. In overall analysis battery operated auto-rickshaws and rickshaws are causing unbearable traffic jam in Rajshahi city by illegally parking near markets and other institutions. There are inadequate traffic police to supervise the busiest points in the city. Therefore, the authority of City Corporation must limited the number of rickshaw and autorickshaw and issued license according to the requirement of vehicles of daily city dwellers. Three major intersection has enough effective carriageway width to meet the traffic demand but only one intersection that mean "Monichottor" is the worst intersection to fail the traffic demand. Some regulatory measures such as pricing, angle parking, improve in management system, traffic policy etc. should be taken to control illegal on street parking. Finally parking is a crying need issue in modern world. In recent time parking demand increasing day by day in Rajshahi. It is not only present concern but also a great concern in future to meet its own demand.

\section{References}

[1] Basri, A., Khatun, T., Reza, M. S. and Khan, M. M. H. (n. d). Changing Modes of Transportation: A Case Study of Rajshahi City Corporation, Retrieved December 18, 2017, from http://bea-bd.org/site/images/pdf/ 029.pdf

\section{Biography}

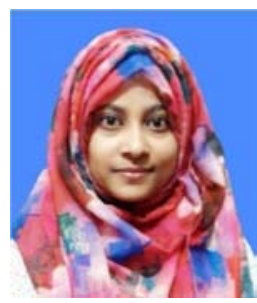

Aftabun Nahar was born in Chapai Nawabganj, Bangladesh in 1995. She received her Secondary and Higher Secondary School Certificate in 2011 and 2013 respectively. She is an undergraduate student at Department of Urban and Regional Planning in Rajshahi University of Engineering and Technology (RUET), Rajshahi-6204, Bangladesh. She attended on several GIS and Remote Sensing based training program and workshop, United MUN 2015, Consultation program on Environmental Protection etc. Her research and publication interest include Tourism Planning and Management, Traffic and Transportation Planning, Environmental Planning and Management, Rural Planning and Water Resource Management.
[2] Rahim, M. A., Joardder, M. Z. H., Hoque. S. M. N., Rahman, M. M. and Sumon, N. H. (2013. February). Socio-economic and environmental impacts of battery driven auto rickshaw at Rajshahi city in Bangladesh. International Conference on Mechanical, Industrial and Energy Engineering 2012 (ICMIEE-2012 KUET). 01-02 February, 2013, Khulna, Bangladesh.

[3] Mandal, S., Ahmed, S. and Rabbi, F. (2015). Impact of battery driven vehicle on the electricity of Rajshahi city, Bangladesh. International Conference on Mechanical, Industrial and Materials Engineering 2015 (ICMIME 2015). 11-13 Dec 2015, RUET, Rajshahi, Bangladesh.

[4] Kadiyali, L. R. (2007). Traffic Engineering and Transport Planning (7th Edition ed.). Delhi: Khanna Publishers.

[5] Center City, Philadelphia Parking Inventory Report (2015). Philadelphia City Planning Commission.

[6] Traffic Level of Service Calculation Methods: Retrieved December 22, 2017, from http://ccag.ca.gov/wpcontent/uploads/2014/07/cmp_2005_Appendix_B.pdf

[7] Litman, T. A. (2012). Parking Management - Strategies, Evaluation and Planning. Retrieved September 19, 2013, from Victoria Transport Policy Institute: http://www.vtpi.org/park_man.pdf

[8] Tanzim S. M. Z. and Miah M. M. (2016). Study of Parking Accumulation in Major on Street Parking Spots in Rajshahi City, Bangladesh. Journal of Construction and Building Materials Engineering, 2(1), 1-15.

[9] Zannat, E. K., Ahmed, T., Mitra, S. K., Rafiq, R., Hasan, M. A., Akhter, K. and Fahad, Z. H. (2013, December). Parking Demand and Supply Analysis of Major Shopping Centers in Dhaka - A Case Study of New Market Shopping Center along Mirpur Road. Journal of Bangladesh Institute of Planners, 6, 161-172.

[10] Banu, M. M. and Rahman, M. M. (2016). Demand and Supply of Parking Facility and the Effects of on Street Parking on Roadway Capacity. Proceedings of 3rd International Conference on Advances in Civil Engineering, 21-23 December 2016, CUET, Chittagong, Bangladesh.

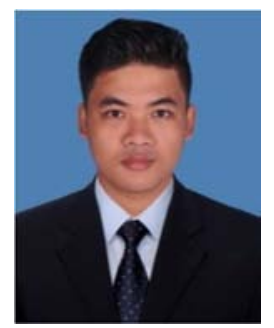

Rupesh Chakma was born in Rangamati, Bangladesh in 1995. He received his Secondary and Higher Secondary School Certificate in 2011 and 2013 respectively. $\mathrm{He}$ is an undergraduate student at Department of Urban and Regional Planning in Rajshahi University of Engineering and Technology (RUET), Rajshahi-6204, Bangladesh. He attended on several GIS and Remote Sensing based training program and workshop. His research and publication interest include Traffic and Transportation Planning, Environmental Planning and Management, Regional Planning. 


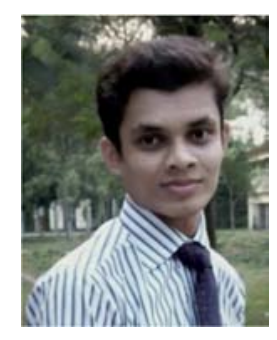

Nayem Uddin was born in Rajshahi, Bangladesh in 1993. He received his Secondary and Higher Secondary School Certificate in 2010 and 2012 respectively. $\mathrm{He}$ is an undergraduate student at Department of Urban and Regional Planning in Rajshahi University of Engineering and Technology (RUET), Rajshahi-6204, Bangladesh. He attended on several GIS and Remote Sensing based training program and workshop. His research and publication interest include Traffic and Transportation Planning, Environmental Planning and Management and regional planning.

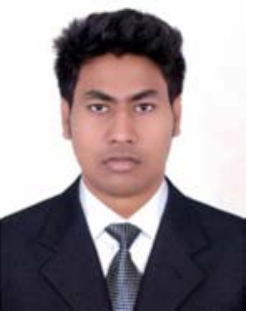

Anutosh Das is a Faculty Member working in the Department of Urban \& Regional Planning at Rajshahi University of Engineering \& Technology (RUET), Bangladesh since 2016. He received his BURP degree from Bangladesh University of Engineering and Technology (BUET), in 2015. Mr. Das is an Associate Member of the Bangladesh Institute of Planners (BIP). His current research interests include Natural Hazard \& Disaster Risk Management, Spatial Analysis, Land Use Planning and Natural Resource Management. His profound academic and professional background focuses on the sound assimilation of global economic and sociopolitical context in mainstreaming governance issues as an adaptive measure of global climate change. 